Brazilian Journal

of Chemical

ISSN 0104-6632

Engineering

\title{
SYNTHESIS AND PHYSICOCHEMICAL CHARACTERIZATION OF TITANIUM OXIDE AND SULFATED TITANIUM OXIDE OBTAINED BY THERMAL HYDROLYSIS OF TITANIUM TETRACHLORIDE
}

\author{
H. Esteban Benito ${ }^{1}$, T. Del Ángel Sánchez ${ }^{1}$, R. García Alamilla ${ }^{1 *}$, J. M. Hernández \\ Enríquez ${ }^{1}$, G. Sandoval Robles ${ }^{1}$ and F. Paraguay Delgado ${ }^{2}$ \\ ${ }^{1}$ Instituto Tecnológico de Ciudad Madero, División de Estudios de Posgrado e Investigación, Juventino \\ Rosas y Jesús Urueta s/n, Col. Los Mangos, C.P. 89440, Ciudad Madero, Tamaulipas, México. \\ Phone: + (52) 833 357-48-20, Fax: + (52) 833 357-48-20 \\ E-mail: rgalamilla@yahoo.com.mx \\ ${ }^{2}$ Centro de Investigación en Materiales Avanzados, Av. Miguel Cervantes \# 120, \\ Complejo Industrial, C.P. 31109, Chihuahua, Chihuahua, México.
}

(Submitted: January 21, 2013 ; Revised: September 18, 2013 ; Accepted: September 27, 2013)

\begin{abstract}
This work reports the synthesis of titanium oxide $\left(\mathrm{TiO}_{2}\right)$ and sulfated titanium oxide $\left(\mathrm{TiO}_{2}-\mathrm{SO}_{4}{ }^{2-}\right)$ obtained by thermal hydrolysis of titanium tetrachloride. Titanium hydroxide synthesized by this method was impregnated with a $1 \mathrm{~N} \mathrm{H}_{2} \mathrm{SO}_{4}$ solution, to give amounts of sulfate ions $\left(\mathrm{SO}_{4}^{2-}\right)$ of 3 and $7 \mathrm{wt} \%$. The synthesized samples were dried at $120^{\circ} \mathrm{C}$ during $24 \mathrm{~h}$ and then calcined for $3 \mathrm{~h}$ at $400{ }^{\circ} \mathrm{C}$. Thermal analyses, $\mathrm{X}$-ray diffraction, nitrogen physisorption, infrared spectroscopy, potentiometric titration with $n$-butylamine, U.V.-visible diffuse reflectance spectroscopy and scanning electron microscopy were used to characterize the materials. The results of physicochemical characterization revealed that a mixture of crystalline structures, anatase, brookite and rutile developed in the titanium oxide, stabilizing the anatase structure in the sulfated titanium oxides, and coexisting with a small amount of brookite structure. The synthesized mesoporous materials developed specific surface areas between 62 and $70 \mathrm{~m}^{2} \mathrm{~g}^{-1}$, without detecting an important influence of sulfation on this parameter. The presence of sulfate ions improved the acidity of titanium oxide and modified the characteristics of light absorption in the 425-600 nm region, which suggests the possibility of using these materials in reactions assisted by visible light.
\end{abstract}

Keywords: Titanium oxide; Thermal hydrolysis; Sulfation; Physicochemical characterization.

\section{INTRODUCTION}

Titanium oxide $\left(\mathrm{TiO}_{2}\right)$ is a widely studied ceramic material and its applications depend on its physicochemical properties such as crystalline structure, particle size, surface area, porosity and thermal stability (Yanting et al., 2009). Depending on material properties, the $\mathrm{TiO}_{2}$ can be used as catalyst, photocatalyst, in applications in photovoltaic cells, gas sensors, solar panels, etc. (Congxue et al., 2008; Zheng et al., 2009). Titanium oxide presents three crystalline phases, anatase, brookite and rutile, which depend on the fine control of some synthesis parameters such as preparation method, precursor used,

*To whom correspondence should be addressed 
solvent/precursor ratio, stirring speed, aging time, calcination temperature, etc. (Addamo et al., 2005). Research on titanium oxide has focused on stabilizing the tetragonal-anatase phase in this oxide due to its excellent catalytic properties (Nolph et al., 2007; Pedraza et al., 2009). Together with this, the control of morphological properties is also essential for material reactivity (Yuan et al., 2002; Addamo et al., 2004). The literature reports several synthetic methods to obtain titanium oxide with tetragonal-anatase structure and controlled morphological properties; the most important are the sol-gel method, hydrolysis of inorganic salts, ultrasound technique, micro-emulsion method or reverse micelle and some hydrothermal processes (Kim et al., 2007; Lu et al., 2008; Štengl et al., 2008; Štengl et al., 2010). The sol-gel method and hydrothermal process are the most common synthetic routes used to prepare the transition metal oxide previously mentioned (Chuang et al., 2009; Collazzo et al., 2011). Different polar and non-polar solvents have been used in these processes to obtain titanium hydroxide, which is calcined in the range of temperature between $200{ }^{\circ} \mathrm{C}$ and $600{ }^{\circ} \mathrm{C}$ to crystallize the anatase phase of $\mathrm{TiO}_{2}($ Sivakumar et al., 2002; Akarsu et al., 2006). However, some disadvantages of the sol-gel method and hydrothermal processes have been recently pointed out in their application as synthetic methods; the first method is related to high production costs and low reproducibility, the second method requires specialized equipment for synthesis and also high temperatures and pressures (Chuang et al., 2009). Due to this, the thermal hydrolysis method is an alternative for the titanium oxide synthesis. Matijevic et al. (1977) prepared a titanium oxide sol precursor with very homogenous particle size distribution by means of aging a very acid solution of $\mathrm{TiCl}_{4}$ at $95^{\circ} \mathrm{C}$, using sulfate ions as control agent. Kato et al. (1989) synthesized spherical titanium oxide particles from an aqueous solution of $\mathrm{TiOSO}_{4}$ and urea as precipitating reagent, carrying out the material synthesis between 70 and $90{ }^{\circ} \mathrm{C}$. The amorphous hydroxygel crystallized in the anatase structure at temperatures below $500{ }^{\circ} \mathrm{C}$ and in rutile when the material was calcined at temperatures greater than $900{ }^{\circ} \mathrm{C}$. Serpone et al. (1995) reported nanometric titanium oxide synthesis by controlled hydrolysis of $\mathrm{TiCl}_{4}$ at $0{ }^{\circ} \mathrm{C}$, which led to obtain an oxide with anatase structure and uneven particle size. Park et al. (1996) reported thermal hydrolysis of $\mathrm{Ti}\left(\mathrm{SO}_{4}\right)_{2}$ at $80{ }^{\circ} \mathrm{C}$ in a mixture of 1-propanol and water, obtaining the anatase structure when the amorphous-hydrated precursor was calcined below $600{ }^{\circ} \mathrm{C}$ and rutile for calcination temperatures above $800^{\circ} \mathrm{C}$. Iwasaki et al. (1998) synthesized nanocrystalline titanium oxide with anatase structure by thermal hydrolysis of titanyl sulfate in a water/alcohol solution; adjusting the synthesis conditions such as water/alcohol ratio and reflux time it was possible to obtain crystal sizes between 2 and $7 \mathrm{~nm}$. Recently, $\mathrm{Xu}$ et al. (2008) synthesized titanium oxide microtubes modified with nitrogen from titanium tetrachloride, using ammonium hydroxide as precipitant. The material obtained after calcination at $500{ }^{\circ} \mathrm{C}$ showed high thermal stability and good photocatalytic behavior in degradation of phenol and methyl orange, irradiating the test solution with visible and ultraviolet light. Kozlov et al. (2000) noted that titanium oxides synthesized from the hydrolysis of titanium tetrachloride have high surface acidity, which increased its catalytic activity in the photo-oxidation of ethanol in the gaseous phase. It has been reported that doping titanium oxide with metal oxides such as $\mathrm{WO}_{3}$ improves the acidic properties of the material and increases its photocatalytic activity (Cui et al., 1995). Other studies also support the idea that one of the ways to improve the photocatalytic performance is by increasing the number and strength of acid sites in the catalysts (Colón et al., 2003; Kozlov et al., 2003).

For these reasons, in this work titanium oxide synthesis from thermal hydrolysis of titanium tetrachloride and the sulfation effect on the physicochemical properties of material are investigated.

\section{EXPERIMENTAL}

\section{Materials}

The following chemical reagents were used for the synthesis of titanium oxides: Titanium tetrachloride $\left(\mathrm{TiCl}_{4}, \mathrm{~J}\right.$. T. Baker, analytical reagent grade), hydroxy-propyl-cellulose (Aldrich, nominal molecular weight of 100,000 $\mathrm{g} \mathrm{mol}^{-1}$ ), anhydrous 2-propanol $\left(\left(\mathrm{CH}_{3}\right)_{2} \mathrm{CHOH}\right.$, Aldrich, $99.5 \%$ purity), anhydrous ethanol $\left(\mathrm{CH}_{3} \mathrm{CH}_{2} \mathrm{OH}\right.$, Aldrich, $99.5 \%$ purity), ammonium hydroxide solution $\left(\mathrm{NH}_{4} \mathrm{OH}\right.$, Fermont, $30 \mathrm{wt} . \%$ purity), sulfuric acid $\left(\mathrm{H}_{2} \mathrm{SO}_{4}\right.$, Fermont, 97 wt.\% purity) and deionized water $\left(\mathrm{H}_{2} \mathrm{O}\right.$, Fermont).

\section{Titanium Oxide Synthesis $\left(\mathrm{TiO}_{2}\right.$ and $\mathrm{TiO}_{2}-\mathrm{SO}_{4}{ }^{2-}$ )}

To synthesize the precursor of titanium oxide $\left[\mathrm{Ti}(\mathrm{OH})_{4}\right], 0.015 \mathrm{~g}$ of hydroxy-propyl-cellulose were dissolved in a solution constituted by $6 \mathrm{~mL}$ of deionized water and $9 \mathrm{~mL}$ of isopropyl alcohol. Subsequently, the solution was cooled to $4{ }^{\circ} \mathrm{C}$ to proceed slowly, adding dropwise, $21 \mathrm{~mL}$ of an aqueous solu- 
tion of $\mathrm{TiCl}_{4} 3 \mathrm{M}$. The solution was homogenized by gentle stirring and heated at $70{ }^{\circ} \mathrm{C}$ during $1 \mathrm{~h}$. Finally, $15 \mathrm{ml}$ of a $\mathrm{NH}_{4} \mathrm{OH}$ solution $(30 \mathrm{wt} \%)$ were added to precipitate the $\mathrm{Ti}(\mathrm{OH})_{4}$, maintaining the system under constant stirring for $1 \mathrm{~h}$ at $70{ }^{\circ} \mathrm{C}$. The precipitate was aged at room temperature during $24 \mathrm{~h}$ and subsequently was filtered and washed with deionized water and ethyl alcohol to remove residuals from the synthesis. The material recovered from the filtration was dried at $120{ }^{\circ} \mathrm{C}$ for $24 \mathrm{~h}$, obtaining $\mathrm{Ti}(\mathrm{OH})_{4}$, which was calcined under a static air atmosphere at $400{ }^{\circ} \mathrm{C}$ for $3 \mathrm{~h}$ to obtain the stabilized titanium oxide $\left(\mathrm{TiO}_{2}\right)$, material that, from this point on, will be designed as TOS.

To obtain sulfated titanium oxide $\left(\mathrm{TiO}_{2}-\mathrm{SO}_{4}{ }^{2-}\right)$, the $\mathrm{Ti}(\mathrm{OH})_{4}$ was impregnated by incipient wetness method using a $1 \mathrm{~N} \mathrm{H}_{2} \mathrm{SO}_{4}$ solution, adding the required solution volume to obtain materials with theoretical sulfate ion contents of 3 and $7 \mathrm{wt} . \%$. The resulting material after impregnation was dried at $120{ }^{\circ} \mathrm{C}$ for $24 \mathrm{~h}$ and it was calcined at $400{ }^{\circ} \mathrm{C}$ for $3 \mathrm{~h}$. The obtained materials were named $\mathrm{T} 3 \mathrm{~S}$ and $\mathrm{T} 7 \mathrm{~S}$, respectively.

\section{Materials Characterization}

The physicochemical characterization of synthesized materials was performed by thermogravimetry, X-ray diffraction, nitrogen physisorption, infrared spectroscopy, potentiometric titration with $n$-butylamine, U.V.-visible diffuse reflectance spectroscopy and scanning electron microscopy.

The thermal analyses were performed using a thermogravimetric balance TA Instruments STD 2960 Simultaneous DSC-TGA at a heating rate of $10{ }^{\circ} \mathrm{C} \mathrm{min}{ }^{-1}$ under an air atmosphere.

$\mathrm{X}$-ray diffraction patterns of the synthesized materials were obtained in a Siemens D500 diffractometer which used $\mathrm{Cu} \mathrm{K \alpha}(\lambda=1.5406 \AA)$ radiation. The samples were evaluated in the range of $20-80^{\circ}$ on the $2 \theta$ scale with a step size of $0.02^{\circ}$ and a measuring time of $2.7 \mathrm{~s}$ per point. The diffraction patterns were compared with a database contained in the software of the equipment that matches the reference records of the Joint Committe of Powder Diffraction Standard (JCPDS).

The textural properties of the materials were assessed by means of nitrogen physisorption at $-196{ }^{\circ} \mathrm{C}$ in a Quantachrome Autosorb-1 instrument. Prior to the measurements, samples were outgassed at $300^{\circ} \mathrm{C}$ for $2 \mathrm{~h}$.

Infrared spectroscopy was carried out in a Fourier Transform Spectrometer (Perkin-Elmer Spectrum One) with transparent wafers containing the sample to be analyzed and $\mathrm{KBr}$ as binder (9:1 dilution). Spectra were recorded at a resolution of $4 \mathrm{~cm}^{-1}$ and by co-adding 16 scans.

The surface acidity was determined by potentiometric titration with $n$-butylamine. A small quantity of $0.025 \mathrm{M} n$-butylamine in acetonitrile was added to a known mass of solid, which was suspended in the solution and stirred for $3 \mathrm{~h}$. After this, the suspension was titrated with the same base at a rate of $0.2 \mathrm{~mL}$ $\min ^{-1}$.

The U.V.-visible diffuse reflectance spectra of the samples were obtained with a Shimadzu U.V.-2401 spectrophotometer using $\mathrm{BaSO}_{4}$ as the reference sample. The spectra were recorded in the range 200 $800 \mathrm{~nm}$.

The morphological characterization of the synthesized materials was performed by scanning electron microscopy using a JEOL JSM-5800 LV microscope.

\section{RESULTS AND DISCUSSION}

\section{Thermal Analyses}

Figure 1 represents the thermal evolution of the precursors of pure and sulfated titanium oxides. In the thermal profiles, different weight loss stages can be detected. The first was in the range from room temperature to $200{ }^{\circ} \mathrm{C}$, related with the elimination of physisorbed water and ammonium chloride, remanents of the material synthesis (Monroy et al., 2007). The second stage of weight loss located between 200 and $350{ }^{\circ} \mathrm{C}$ could be attributed to combustion of the structural agent (hydroxy-propyl-cellulose) and a partial dehydroxylation of $\operatorname{Ti}(\mathrm{OH})_{4}$, which could lead to transformation from an amorphous phase to a crystalline structure of $\mathrm{TiO}_{2}$ (Sivakumar et al., 2002).

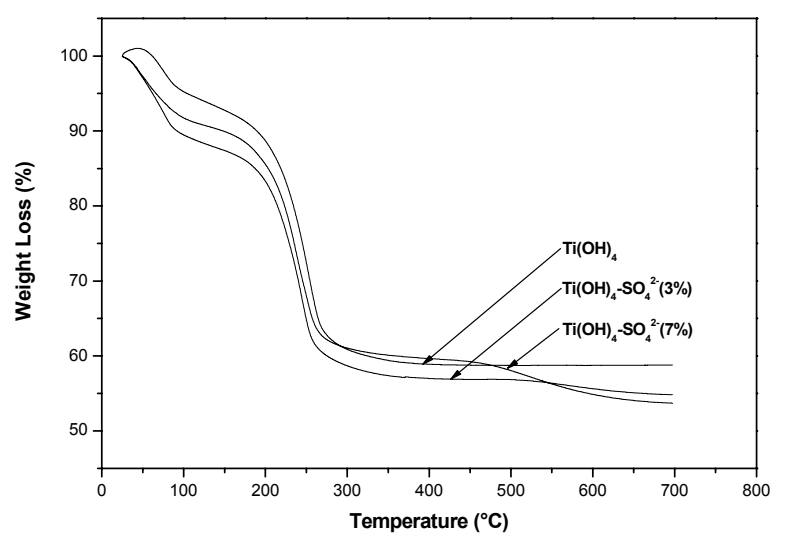

Figure 1: Thermogravimetric analysis of synthesized titanium hydroxides. 
These two first weight loss stages are similar in the pure and sulfated titanium oxide precursors, showing a weight loss of $40 \%$ in the three materials. The pure titanium oxide precursor did not show any more changes in the thermogravimetric profile, in contrast with the sulfated precursors, which presented an additional weight loss stage in the range of $350-700{ }^{\circ} \mathrm{C}$ associated with elimination of sulfate ions (Ciambelli et al., 2008). Based on the results of the thermogravimetric analyses, it can be deduced that the presence of sulfate ions in the titanium oxide structure can be considered only for samples calcined below $500{ }^{\circ} \mathrm{C}$.

\section{X-Ray Powder Diffraction}

The X-ray diffraction patterns of the synthesized titanium oxides can be observed in Figure 2. Pure titanium oxide is constituted of a mixture of anataserutile phases, both with tetragonal structure and also traces of orthorhombic brookite, according to data reported in the database cards 00-021-1276, 00-0211272 and $00-029-1360$. In sulfated materials the anatase phase was obtained in greater proportion, although there is a persistent signal at $30.68^{\circ}$ on the $2 \theta$ scale referred to plane $\left(\begin{array}{lll}2 & 1 & 1\end{array}\right)$ which is characteristic of the orthorhombic brookite phase of titanium oxide. In studies made by $\mathrm{Hu}$ et al. (2003) on the phase composition of titanium oxides, it was found that the fraction of brookite phase increased with decreasing $\mathrm{pH}$ value of the synthesis. The formation of $\mathrm{HCl}$ or $\mathrm{NH}_{4} \mathrm{Cl}$ during precipitation of titanium hydroxide may have allowed the formation of this crystal structure, in agreement with results reported by Pottier et al. (2001), who mentioned that in very acidic solutions of $\mathrm{TiCl}_{4}, \mathrm{Cl}^{-}$ions stabilize brookite nanoparticles.

It was also observed that the incorporation of sulfate ion into the titanium oxide structure caused a stabilizing effect of the anatase phase, inhibiting the formation of the rutile phase at the thermal treatment temperature reported in this work.

The average crystallite size of the samples was calculated from the most intense diffraction peak (101) of anatase $\mathrm{TiO}_{2}$ using the Scherrer formula, which is expressed in Equation (1):

$D=\frac{0.9 \lambda}{\beta \cos \theta}$

In this equation, $D$ is the crystallite size in angstroms, $\lambda$ is the radiation wavelength used $(\lambda=$ $1.5106 \AA), \theta$ is the Bragg angle and $\beta$ is the full width at half-height of the diffraction peak (101). The values of the crystallite sizes are provided in Figure 2. The synthesized titanium oxide series (sulfated and non-sulfated) present mean crystallite sizes in the nanometer range $(8-14 \mathrm{~nm})$. It can be noted that the crystallite size slightly decreases due to sulfation of the samples. Thus, the results reveal that sulfate ions anchored to the $\mathrm{TiO}_{2}$ surface cause a steric effect that retards the particle growth; a similar effect has been reported by Yan et al. (2005).

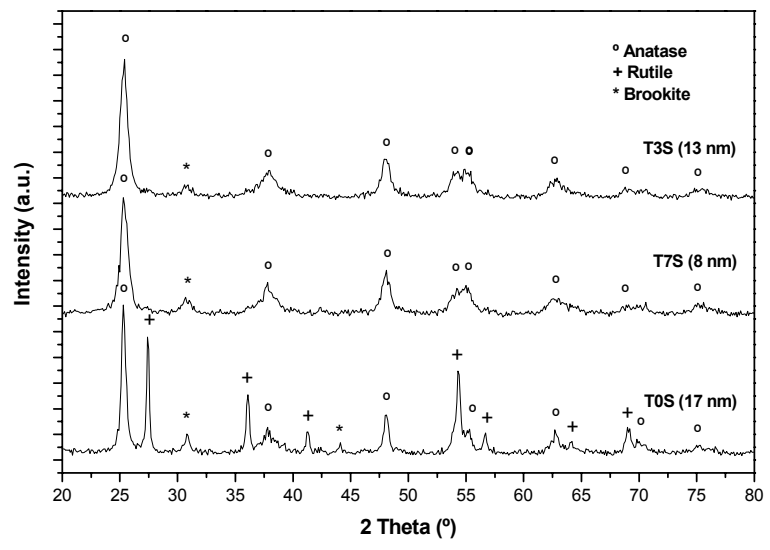

Figure 2: XRD pattern of the synthesized titanium oxides $\left(\mathrm{TiO}_{2}\right.$ and $\left.\mathrm{TiO}_{2}-\mathrm{SO}_{4}{ }^{2-}\right)$.

\section{Textural Properties}

The three synthesized titanium oxides showed type IV isotherms, characteristic of mesoporous solids (Figure 3 ). The hysteresis cycle for pure titanium oxide corresponds to the H1 type, according to the IUPAC classification, characterized by having almost vertical and nearly parallel branches of adsorptiondesorption over an appreciable range of relative pressures.

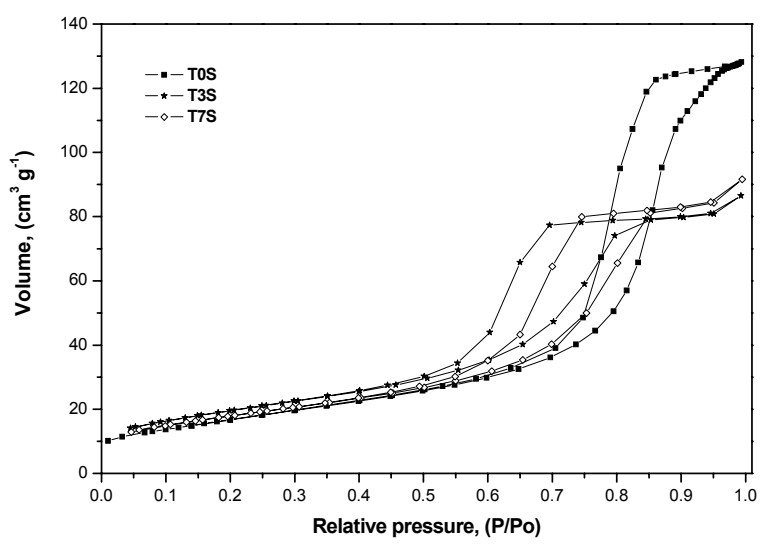

Figure 3: Nitrogen adsorption-desorption isotherms of the synthesized titanium oxides $\left(\mathrm{TiO}_{2}\right.$ and $\mathrm{TiO}_{2}-$ $\mathrm{SO}_{4}{ }^{2-}$ ). 
The materials that develop this type of hysteresis are characteristic of solids consisting of particles crossed by nearly cylindrical channels or made up of aggregates (consolidated) or agglomerates (unconsolidated) of spheroidal particles (Leofanti et al., 1998). The addition of the sulfate ion modified essentially the nitrogen desorption phenomenon in the materials $\mathrm{T} 3 \mathrm{~S}$ and $\mathrm{T} 7 \mathrm{~S}$, obtaining wider hysteresis cycles corresponding to the $\mathrm{H} 2$ type, which are characteristic of materials with nonuniform pore size and shape (Sing et al., 1985; Leofanti et al., 1998). The three synthesized materials showed a monomodal pore size distribution centered in the mesoporous region (Figure 4).

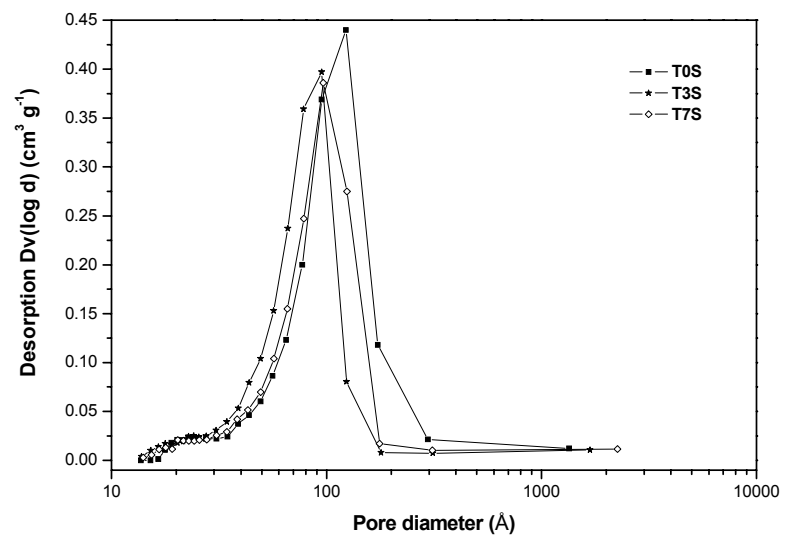

Figure 4: Pore size distribution of the synthesized titanium oxides $\left(\mathrm{TiO}_{2}\right.$ and $\left.\mathrm{TiO}_{2}-\mathrm{SO}_{4}{ }^{2-}\right)$.

Table 1 summarizes the textural parameters of the studied materials. The addition of the sulfate ion modified slightly the textural properties of the titanium oxide. The specific surface area increased from $62 \mathrm{~m}^{2} \mathrm{~g}^{-1}$, the value obtained with the material T0S, up to $70 \mathrm{~m}^{2} \mathrm{~g}^{-1}$ for T3S. However, an increase in the amount of sulfate ions had a negative impact on the specific surface area of the material, decreasing the value to $65 \mathrm{~m}^{2} \mathrm{~g}^{-1}$ for the T7S material in the nitrogen physisorption. In the sulfated titanium oxides (T3S and T7S) pore diameters were smaller in comparison with pure titanium oxide (TOS). According to the results shown in Table 1, the sulfated species attached to the titanium oxides delayed the material sinterization.

Table 1: Textural properties of the synthesized titanium oxides.

\begin{tabular}{|c|c|c|c|}
\hline Material & $\begin{array}{c}\text { Surface area } \\
\left(\mathbf{m}^{\mathbf{2}} \mathbf{g}^{\mathbf{- 1}} \mathbf{)}\right.\end{array}$ & $\begin{array}{c}\text { Pore diameter } \\
(\mathbf{\AA})\end{array}$ & $\begin{array}{c}\text { Pore volume } \\
\left(\mathbf{c m}^{\mathbf{3}} \mathbf{g}^{\mathbf{- 1}} \mathbf{)}\right.\end{array}$ \\
\hline T0S & 62 & 123 & 0.120 \\
T3S & 70 & 95 & 0.115 \\
T7S & 65 & 97 & 0.125 \\
\hline
\end{tabular}

\section{Infrared Spectroscopy}

The infrared spectroscopic analysis shown in Figure 5 allowed identification of the functional groups present in the synthesized materials. Pure and sulfated titanium oxides showed signals in their infrared spectra located at 1627, 1610 and $641 \mathrm{~cm}^{-1}$. The first two are attributed to the bending mode of (H-O-H)- related to water molecules adsorbed on the material's surface and the latter is associated with the stretching modes of Ti-O bonds, which are characteristic of titanium oxide (Skoog and Leary, 2003). The materials T3S and T7S showed absorption bands at 1224,1142 and $1050 \mathrm{~cm}^{-1}$, which identify the presence of bidentate sulfate ion coordinated to the metal cation $\mathrm{Ti}^{4+}$. In the literature, metallic oxides modified with sulfate ions and thermally treated at $400{ }^{\circ} \mathrm{C}$ show a band near $1390-1370 \mathrm{~cm}^{-1}$ that corresponds to a stretching vibration mode caused by $\mathrm{S}=\mathrm{O}$ bonds (Sohn et al., 2004). The absence of this signal in the synthesized materials is related to water adsorption on the solid surface; this result agrees with that reported by other authors (Saour et al., 1986; Morrow et al., 1987; Yamaguchi, 1990).

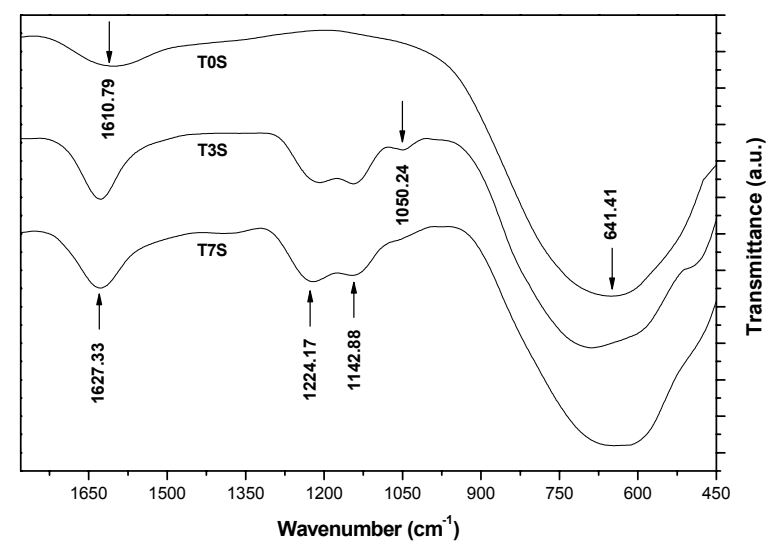

Figure 5: FT-IR spectra of synthesized titanium oxides $\left(\mathrm{TiO}_{2}\right.$ and $\left.\mathrm{TiO}_{2}-\mathrm{SO}_{4}{ }^{2-}\right)$.

\section{Surface Acidity}

Potentiometric titration with $n$-butylamine allowed assessing the total amount of acid sites as well as maximum acid strength of the materials. The maximum acid strength is determined at the first reading point of the electrode potential $(\mathrm{E})$ and can be expressed in millivolts $(\mathrm{mV})$. The number of acid sites present in the materials is determined by the amount of base used, which is expressed in milliequivalents of titrant used per gram of solid ( $n$-bta meq $\left.\mathrm{g}^{-1}\right)$. The strength of the acid sites is assigned according to the scale reported by Pizzio et al. 
(2001): $\mathrm{E}>100 \mathrm{mV}$ (very strong acid sites), $0<\mathrm{E}<$ $100 \mathrm{mV}$ (strong acid sites), $-100<\mathrm{E}<0 \mathrm{mV}$ (weak acid sites), and $\mathrm{E}<-100 \mathrm{mV}$ (very weak acid sites). Figure 6 shows the neutralization profile of the acid sites present in the synthesized materials by potentiometric titration with $n$-butylamine. This figure shows that sulfate ions incorporated in the structure of the titanium oxide increase the acidity of the material, generating strong and very strong acid sites on its surface. Also a remarkable difference related to acidity can be observed between pure titanium oxide (T0S) and the modified materials (T3S and T7S). The modified materials, due to the presence of sulfate ions, showed a maximum acid strength around $540 \mathrm{mV}$, while pure titanium oxide (TOS) only reached a maximum acid strength of $100 \mathrm{mV}$. The total amount of milliequivalents of $n$-butylamine used per gram of material confirmed that the acid site concentration is higher in the sulfated materials than in the pure titanium oxide. According to the amount of base used and to the neutralization profile observed, it can be said that the material T7S is the one with the highest concentration of acid sites and a population of very strong acid sites greater than the other two synthesized materials.

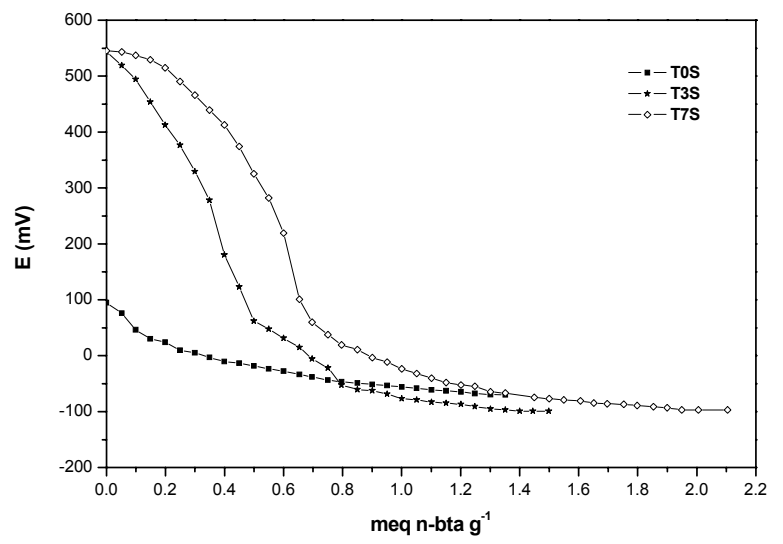

Figure 6: Potentiometric titration profiles performed on the synthesized titanium oxides $\left(\mathrm{TiO}_{2}\right.$ and $\mathrm{TiO}_{2}-$ $\mathrm{SO}_{4}{ }^{2-}$ ).

\section{U.V.-Vis Diffuse Reflectance Spectroscopy}

Figure 7 shows the U.V.-Vis spectra with diffuse reflectance of pure titanium oxide (T0S) and both materials modified with sulfate ions (T3S and T7S). For TOS the spectrum is characterized by an absorption band between 250 and $420 \mathrm{~nm}$, obtaining for this material a band-gap energy value of $3.02 \mathrm{eV}$. Commercial Degussa P-25 titanium oxide is composed of $70 \%$ of anatase phase and $30 \%$ rutile phase and in the literature it has been reported that its band- gap energy value is $3.2 \mathrm{eV}$ (López and Gómez, 2012). While the value of the titanium oxide with anatase phase coincides with the commercial material, titanium oxide with rutile phase differs in this parameter with a value of band-gap energy of $3.0 \mathrm{eV}$ (Yoon et al., 2006). The presence of the brookite phase in the pure titanium oxide (TOS) synthesized in this work, allowed us to obtain a value of band-gap energy different from the commercial Degussa P-25. When sulfate ions are added in the titanium oxide structure, the material changes its absorption characteristics in the ultraviolet region. Besides this, there is a new absorption region in the spectra between 425-600 $\mathrm{nm}$, which suggests the potential use of these photocatalytic materials in reactions assisted by visible light. The band-gap energy values determined for T3S and T7S were 3.13 and $3.09 \mathrm{eV}$, respectively. These values were obtained using the U.V.-Vis absorption spectra. The optical energy band gap was calculated using equation (2) (Porkodi and Daisy, 2007; Molea and Popescu, 2011):

$$
E_{g}=\frac{h \cdot c}{\lambda}=\frac{1240}{\lambda}
$$

where $E_{g}$ is the band-gap energy $(\mathrm{eV}), h$ the Planck's constant $\left(4.135 \times 10^{-15} \mathrm{eV} . \mathrm{s}\right), c$ the light velocity $\left(2.997 \times 10^{8} \mathrm{~m} \mathrm{~s}^{-1}\right)$ and $\lambda$ the band gap wavelength of titanium oxides $(\mathrm{nm})$.

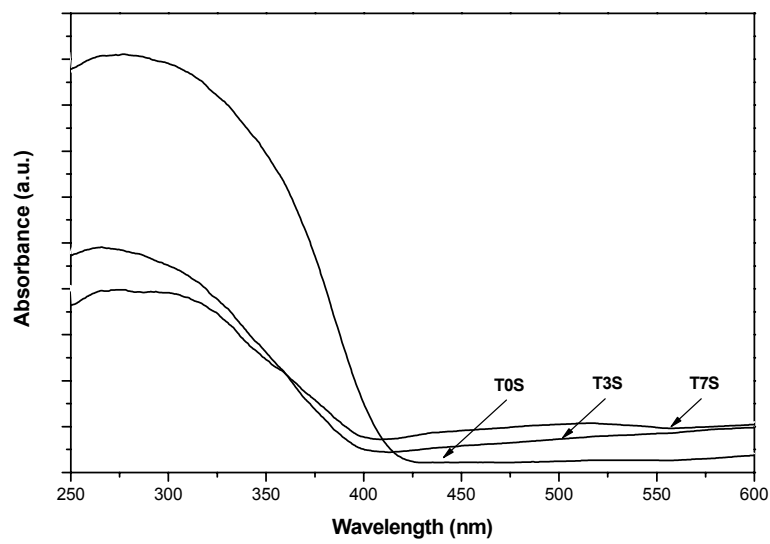

Figure 7: U.V.-Visible diffuse reflectance spectra of the synthesized titanium oxides $\left(\mathrm{TiO}_{2}\right.$ and $\left.\mathrm{TiO}_{2}-\mathrm{SO}_{4}{ }^{2-}\right)$.

\section{Scanning Electron Microscopy}

Figure 8 shows the scanning electron microscopy images obtained with the synthesized titanium oxides, taken with a magnification of 500X. It can be seen that pure titanium oxide (TOS) is composed of both big, 40-50 $\mu \mathrm{m}$, and small, 5-10 $\mu \mathrm{m}$, grains with 
different shapes. But what they have in common is their angularity, very sharp edges and well defined facets. When the phase of the titanium oxide precursor is modified with sulfate ions and then calcined at $400{ }^{\circ} \mathrm{C}$, there originate materials of irregular shapes with sharp edges and smaller particle sizes compared with those obtained in pure titanium oxide. Sulfated titanium oxides (T3S and T7S) showed particle sizes in the range between 5 and $25 \mu \mathrm{m}$. The particle size decrease reflects the influence of the sulfate ions on the resistance to material sinterization.
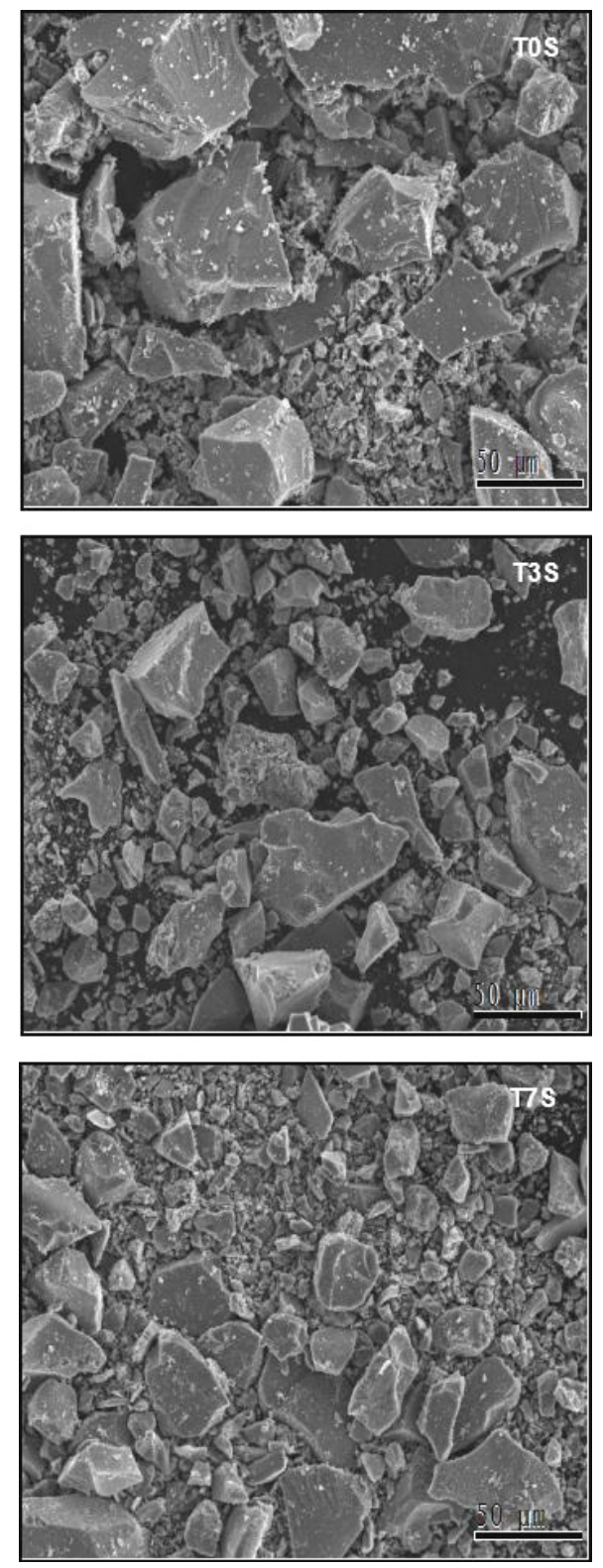

Figure 8: SEM images of the synthesized titanium oxides $\left(\mathrm{TiO}_{2}\right.$ and $\left.\mathrm{TiO}_{2}-\mathrm{SO}_{4}{ }^{2-}\right)$. Images taken with a magnification of $500 \mathrm{X}$.

\section{CONCLUSIONS}

By means of basic hydrolysis of titanium tetrachloride with ammonium hydroxide it was possible to obtain titanium hydroxide, which after calcination under air at $400{ }^{\circ} \mathrm{C}$ led to the formation of a mesoporous titanium oxide, thermally stable, which is constituted of a mixture of crystalline structures anatase, rutile and brookite. The addition of sulfate ions to the titanium oxide structure did not affect its mesoporous condition or its specific surface areas. Nevertheless, the presence of these ions favored stabilization of titanium oxide with the anatase structure, though a small amount of titanium oxide with the brookite structure also persists. The sulfate ions introduced by impregnation increased the titanium oxide acidity and modified the light absorption in the spectral region located between 425-600 nm, which suggests the possibility to use these materials in photocatalytic reactions assisted by visible light. Based on this information, further studies will pursue a detailed analysis of the influence of the brookite structure and the titanium oxide acidity on applications in the field of organic compound degradation.

\section{NOMENCLATURE}

$\begin{array}{llr}\mathrm{D} & \text { Particle size } & \mu \mathrm{m} \\ \mathrm{E} & \text { Electrode potential } & \mathrm{mV} \\ \mathrm{E}_{\mathrm{g}} & \text { Band-gap energy } & \mathrm{eV} \\ \mathrm{S}_{\text {BET }} & \text { Specific surface area } & \mathrm{m}^{2} \mathrm{~g}^{-1} \\ \mathrm{t} & \text { Time } & \mathrm{s}, \mathrm{h} \\ \mathrm{T} & \text { Temperature } & { }^{\circ} \mathrm{C} \\ \mathrm{V} & \text { Volume } & \mathrm{mL}, \mathrm{cm}^{3} \\ \mathrm{wt} & \text { Weight percent } & \%\end{array}$

\section{Greek Symbols}

$2 \theta \quad 2$ theta scale

$\lambda \quad$ Wavelength $\quad \mathrm{nm}, \AA$

$\varphi \quad$ Pore diameter $\AA$ 
T7S

Titanium oxide with $7 \mathrm{wt} \%$ of sulfate ions

TGA Thermogravimetric Analysis

a. u. Arbitrary unit

U.V.-Vis Ultraviolet-visible spectroscopy

XRD X-ray Diffraction

\section{REFERENCES}

Addamo, M., Augugliaro, V., Di Paola, A., García, E., Loddo, V., Marcí, G. and Palmisano, L., Preparation and photoactivity of nanostructured $\mathrm{TiO}_{2}$ particles obtained by hydrolysis of $\mathrm{TiCl}_{4}$. Colloids Surf. A., 265, 23-31 (2005).

Addamo, M., Augugliaro, V., Di Paola, A., García, E., Loddo, V., Marcí, G., Palmisano, L. and Schiavello, M., Preparation, characterization and photoactivity of polycrystalline nanostructured $\mathrm{TiO}_{2}$ catalysts. J. Phys. Chem. B., 108, 3303-3310 (2004).

Akarsu, M., Asiltürk, M., Sayilkan, F., Kiraz, N., Arpaç, E. and Sayilkan, H., A novel approach to the hydrothermal synthesis of anatase titania nanoparticles and the photocatalytic degradation of rhodamine B. Turk. J. Chem., 30, 333-343 (2006).

Chuang, L. Ch., Chang, H. L. and Huang, S. W., Photocatalytic degradation of 4-chlorophenol using prepared $\mathrm{TiO}_{2}$ catalysts. Hung Kuang Journal, 60, 61-73 (2009).

Ciambelli, P., Sannino, D., Palma, V. and Vaiano, $\mathrm{V}$., The effect of sulphate doping on nanosized $\mathrm{TiO}_{2}$ and $\mathrm{MoO}_{x} / \mathrm{TiO}_{2}$ catalysts in cyclohexane photooxidative dehydrogenation. Int. J. Photoenergy, 1, 1-8 (2008).

Collazzo, G. C., Jahn, S. L., Carreño, N. L. V. and Foletto, E. L., Temperature and reaction time effects on the structural properties of titanium dioxide nanopowders obtained via the hydrothermal method. Braz. J. Chem. Eng., 28, 265-272 (2011).

Colón, G., Hidalgo, M. C. and Navío, J. A., Photocatalytic behaviour of sulphated $\mathrm{TiO}_{2}$ for phenol degradation. Appl. Catal., B, 45, 39-50 (2003).

Congxue, T., Zhao, Z., Jun, H. and Ni, L., Surfactant/co-polymer template hydrothermal synthesis of thermally stable, mesoporous $\mathrm{TiO}_{2}$ from $\mathrm{TiOSO}_{4}$. Mater. Lett., 62, 77-80 (2008).

Cui, H., Dwight, K., Soled, S. and Wold, A., Surface acidity and photocatalytic activity of $\mathrm{Nb}_{2} \mathrm{O}_{5} / \mathrm{TiO}_{2}$ Photocatalyst. Solid State Chem., 187, 115-191 (1995).

Hu, Y., Tsai, H. L. and Huang, C. L., Effect of brookite phase on the anatase-rutile transition in titania nanoparticles. J. Eur. Ceram. Soc., 23, 691-696 (2003).

Iwasaki, M., Hara, M. and Ito, S., Facile synthesis of nanocrystalline anatase particles from titanyl sulfate. J. Mater. Sci. Lett., 17, 1769-1771 (1998).

Kato, A., Takeshita, Y. and Katatae, Y., Preparation of spherical titania particles from inorganic precursor by homogeneous precipitation. Mat. Res. Soc. Symp. Proc., 155, 13-22 (1989).

Kim, S. Y., Chang, T. S. and Shin, Ch. H., Enhancing effects of ultrasound treatment on the preparation of $\mathrm{TiO}_{2}$ photocatalysts. Catal. Lett., 118, 224-230 (2007).

Kozlov, D. V., Paukshtits, E. A. and Savinov, E. N., The comparative studies of titanium dioxide in gas-phase ethanol photocatalytic oxidation by the FTIR in situ method. Appl. Catal., B, 24, L7-L12 (2000).

Kozlov, D., Bavykin, D. and Savinov, E., Effect of the acidity of $\mathrm{TiO}_{2}$ surface on its photocatalytic activity in acetone gas-phase oxidation. Catal. Lett., 86, 169-172 (2003).

Leofanti, G., Padovan, M., Tozzola, G. and Venturelli, B., Surface area and pore texture of catalysts. Catal. Today, 41, 207-219 (1998).

López, R. and Gómez, R., Band-gap energy estimation from diffuse reflectance measurements on sol-gel and commercial $\mathrm{TiO}_{2}$ : A comparative study. J. Sol-Gel Sci. Technol., 61, 1-7 (2012).

$\mathrm{Lu}, \mathrm{Ch}$. H. and Wen, M. Ch., Synthesis of nanosized $\mathrm{TiO}_{2}$ powders via a hydrothermal microemulsion process. J. Alloys Compd., 448, 153-158 (2008).

Matijevic, E., Budnick, M. and Meites, L., Preparation and mechanism of formation of titanium dioxide hydrosols of narrow size distribution. J. Colloid Interface Sci., 61, 302-311 (1977).

Molea, A. and Popescu, V., The obtaining of titanium dioxide nanocrystalline powders. Optoelectron. Adv. Mat., 5, 242-246 (2011).

Monroy, F., Cortes, O. and Díaz, H., Titanium molibdate gels as matrix of ${ }^{99} \mathrm{Mo} /{ }^{99 \mathrm{~m}} \mathrm{Tc}$ generators. J. Nucl. Radiochem. Sci., 8, 11-19 (2007).

Morrow, B. A., McFarlane, R. A., Lion, M. and Lavalley, J. C., An infrared study of sulfated silica. J. Catal., 107, 232-239 (1987).

Nolph, Ch. A., Sievers, D. E., Kaewgun, S., Kucera, C. J., McKinney, D. H., Rientjes, J. P., White, J. L., Bhave, R. and Lee, B. I., Photocatalytic study of polymorphic titania synthesized by ambient condition sol process. Catal. Lett., 117, 102-106 (2007).

Park, H. K., Moon, Y. T., Kim, D. K. and Kim, C. $\mathrm{H}$., Formation of mono-disperse spherical $\mathrm{TiO}_{2}$ powders by thermal hydrolysis of $\mathrm{Ti}\left(\mathrm{SO}_{4}\right)_{2}$. J. 
Am. Ceram. Soc., 79, 2727-2732 (1996).

Pedraza, J. A., López, R., Martínez, F., Páez, E. A. and Gómez, R., Effect of chromium doping on visible light absorption of nanosized titania solgel. J. Nano Res., 5, 95-104 (2009).

Pizzio, L., Vázquez, P., Cáceres, C. and Blanco, M., Tungstophosphoric and molybdophosphoric acids supported on zirconium as esterification catalysts. Catal. Lett., 77, 233-239 (2001).

Porkodi, K. and Daisy, S., Synthesis and spectroscopic characterization of nanoestructured anatase titania: A photocatalyst. Mater. Charact., 58, 495-503 (2007).

Pottier, A., Chanéac, C., Tronc, E., Mazerolles, L. and Jolivet, J. P., Synthesis of brookite $\mathrm{TiO}_{2}$ nanoparticles by thermolysis of $\mathrm{TiCl}_{4}$ in strongly acidic aqueous media. J. Mater. Chem., 11, 11161121 (2001).

Saur, O., Bensitel, M., Mohammed, A. B., Lavalley, J. C., Tripp, C. P. and Morrow, B. A., The structure and stability of sulfated alumina and titania. J. Catal., 99, 104-110 (1986).

Serpone, N., Lawless, D. and Khairutdinov, R., Size effects on the photophysical properties of colloidal anatase $\mathrm{TiO}_{2}$ particles: Size quantization versus direct transitions in this indirect semiconductor. J. Phys. Chem., 99, 16646-16654 (1995).

Sing, K. S. W, Everett, D. H., Haul, R. A. W., Moscou, L., Pierotti, R. A., Rouquérol, J. and Siemieniewska, T., Reporting physisorption data for gas/solid systems with special reference to the determination of surface area and porosity. Pure \& Appl. Chem., 57, 603-619 (1985).

Sivakumar, S., Pillai, P., Mukundan, P. and Warrier, K. G. K., Sol-gel synthesis of nanosized anatase from titanyl sulfate. Matt. Lett., 57, 330-335 (2002).

Skoog, D. A. and Leary, J. J., Espectroscopía de absorción en el infrarrojo, In Análisis Instrumental, (Ed.), Mc-Graw Hill, México, p. 328 (2003). (In Spanish).
Sohn, J. R., Lee, S. H., Cheon, P. W. and Kim, H. W., Acidic properties and catalytic activity of titanium sulfate supported on $\mathrm{TiO}_{2}$. Bull. Korean Chem. Soc., 25, 657-664 (2004).

Štengl, V., Bakardjieva, S., Murafa, N. and Houšková, V., Hydrothermal synthesis of titania powders and their photocatalytic properties. Ceramics Silikáty, 52, 278-290 (2008).

Štengl, V., Houšková, V., Murafa, N. and Bakardjieva, S., Synthesis of mesoporous titania by homogeneous hydrolysis of titania oxo-sulfate in the presence of cationic and anionic surfactants. Ceramics Silikáty, 54, 368-378 (2010).

Xu, J. H., Dai, W. L., Li, J., Cao, Y., Li, H., He, H. and Fan, K., Simple fabrication of thermally stable aperture $\mathrm{N}$-doped $\mathrm{TiO}_{2}$ microtubes as a highly efficient photocatalyst under visible light irradiation. Catal. Commun., 9, 146-152 (2008).

Yamaguchi, T., Recent progress in solid superacids. Appl. Catal., 61, 1-25 (1990).

Yan, M., Chen, F., Zhang, J. and Anpo, M., Preparation of controllable crystalline titania and study on the photocatalytic properties. J. Phys. Chem. B., 109, 8673-8678 (2005).

Yanting, L., Xiuguo, S., Huiwan, L., Shaohui, W. and $\mathrm{Yu}, \mathrm{W}$., Preparation of anatase $\mathrm{TiO}_{2}$ nanoparticles with high thermal stability and specific surface area by alcohothermal method. Powder Technol., 194, 149-152 (2009).

Yoon, K. H., Noh, J. S., Kwon, Ch. H. and Muhammed, M., Photocatalytic behavior of $\mathrm{TiO}_{2}$ thin films prepared by sol-gel process. Mater. Chem. Phys., 95, 79-83 (2006).

Yuan, Z. Y., Zhou, W. and Su, B. L., Hierarchical interlinked structure of titanium oxide nanofibers. Chem. Commun., 11, 1202-1203 (2002).

Zheng, R., Meng, X. and Tang, F., Synthesis, characterization and photodegradation study of mixedphase titania hollow submicrospheres with rough surface. Appl. Surf. Sci., 255, 5989-5994 (2009). 